\title{
APRESENTAÇÃO: AINDA SOBRE NOVOS DESCENTRAMENTOS EM OUTRAS AXIALIDADES DA DIVERSIDADE SEXUAL E DE GÊNERO
}

\author{
Fabiano Gontijo (Universidade Federal do Pará) \\ fgontijo2@hotmail.com \\ Estêvão Fernandes (Universidade Federal de Rondônia) \\ estevaofernandes@gmail.com \\ Martinho Tota (Universidade Federal do Ceará) \\ sepolm@gmail.com \\ Moisés Lopes (Universidade Federal do Mato Grosso) \\ martinho.tota@gmail.com
}

Dando continuidade ao primeiro dossiê que publicamos (no volume 8, número 1, de 2016) da Amazônica: Revista de Antropologia do Programa de Pós-Graduação em Antropologia da Universidade Federal do Pará, é com grande satisfação que disponibilizamos, nesse segundo dossiê, mais dez artigos e um ensaio fotográfico 
que tratam - direta ou transversalmente - do que nos propusemos em chamar de "novos descentramentos em outras axialidades" a respeito das experiências da diversidade sexual e de gênero em áreas rurais, contextos interioranos ou periferizados e/ou situações etnicamente diferenciadas no Brasil contemporâneo.

$\mathrm{O}$ país continua a assistir, aparentemente sem muito espanto generalizado, às consequências (mais do que nefastas) do golpe institucional que reforça o regime de verdade hegemônico heteronormativo, branco, masculino, metropolitano, classista, sexista e racista, tendo como implicação a obliteração das pesquisas sobre a diversidade sexual e de gênero, como já apontávamos na apresentação do primeiro dossiê. As pesquisas, cujos resultados são apresentados aqui na forma de artigos, são atravessadas, de alguma forma, pelo contexto vigente de desmonte institucional e organizacional e precarização política e social que acarretam paulatinamente no desvanecimento acadêmico e epistemológico.

O primeiro conjunto de artigos a seguir questiona, de certa maneira, as relações e realidades de gênero a partir de situações de vulnerabilidade, com enfoque nos conhecimentos situados femininos, assim como na resistência das mulheres em áreas rurais ou contextos interioranos e em situações etnicamente diferenciadas das regiões Norte e Nordeste do Brasil. Desse conjunto, fazem parte os artigos de autoria de Lorena Lima de Moraes; ígora Irma Santos Dácio e Milton Ribeiro; Maria de Jesus Silva Sousa, Nelissa Peralta Bezerra, Juliana Menegassi Leoni, Marly das Chagas Oliveira \& Maria Rosenize Assis Amaral; e Arneide Bandeira Cemin. Um segundo conjunto de artigos aponta para a ação dos biopoderes nas conformações das corporalidades e das sexualidades de sujeitos ribeirinhos, interioranos e/ou indígenas do Norte, mas também de sujeitos urbanos de capitais periferizadas do Norte e do Nordeste. Trata-se, nesse conjunto, dos artigos de autoria de Cássio José Sousa Silva, Paulo de Tássio Borges da Silva, e Ana Kelma Cunha Gallas \& Pâmela Laurentina Sampaio Reis.

Questões relativas à interseccionalidade e à (re)produção de desigualdades sociais em situação de imigração e de fronteiras nacionais são muito bem tratadas no artigo de Washington Luiz dos Santos Assis, Adelia Maria Miglievich Ribeiro \& Estêvão Fernandes, enquanto Roberto Marques nos traz, do sertão cearense do Cariri, uma biografia artística um pouco incomum e Barbara Arisi, enfim, apresenta algumas práticas acadêmicas positivas de educação para a diversidade sexual e de gênero no interior fronteiriço paranaense. O dossiê conta ainda com o belíssimo ensaio fotográfico de Pedro Alcântara, Igor Erick e Raiana Ferrugem que mostram, com cores (e quase sons) as experiências das transcorporalidades performativas festivas em Santarém, Pará e com duas resenhas de livros que ajudam ainda mais a contextualizar a temática do dossiê num âmbito mais amplo.

Ao final da leitura desses textos, reforça-se a certeza da necessidade de resistir e de buscar ainda mais "novos descentramentos em outras axialidades" para dar conta do desafio que temos diante de nossos olhos. 